\title{
Taxonomic status of the Guyanese endemic caecilian Caecilia pressula Taylor, 1968 (Amphibia: Gymnophiona: Caeciliidae)
}

\author{
Mark Wilkinson ${ }^{1}$ \\ ${ }^{1}$ Department of Life Sciences, The Natural History Museum, London SW7 5BD, UK
}

\begin{abstract}
The taxonomic status of the poorly known Neotropical caecilian species Caecilia pressula Taylor, 1968 is reconsidered based on examination of the type series. The single reported diagnostic feature, a laterally compressed body, that purportedly distinguishes $C$. pressula from Caecilia tentaculata Linnaeus, 1758 is not consistent across the seven specimens that constitute the type series and the only reported specimens, is variable in the Holotype depending on how it is held, and is considered to be artefactual. Caecilia pressula is considered to be a junior synonym of Caecilia tentaculata. Dentitional features of the smallest and presumed youngest specimens in the type series provide evidence that $C$. tentaculata practices maternal dermatophagy.
\end{abstract}

Keywords: Guyana, neotropics, reproduction, systematics

$\mathrm{C}_{c}^{\circ}$ ompared to many other herpetological taxa, caecilian taxonomy can be challenging. Lack of limbs, and of well-developed eyes and tails limits the number of taxonomic characters, and the relative rarity of many caecilian species in scientific collections limits understanding of variation. Consequently, species limits are sometimes poorly understood. Taxonomic uncertainty is a major reason given for the data deficient conservation status of many caecilian species in the IUCN red list.

The caecilian species Caecilia pressula Taylor, 1968 is one of 13 species of the Neotropical Caecilia Linnaeus, 1758 described by Taylor (1968) in his revision of caecilian taxonomy. The description of $C$. pressula was based on seven specimens in the collections of the American Museum of Natural History (AMNH 4947049076) that were collected from the Marudi Mountains of Guyana by R. Snedigar in 1938 during the TerryHolden Expedition (https://siarchives.si.edu/collections/ auth_exp_fbr_eace0098). A single adult male, AMNH A-49475, was designated the holotype and six much smaller and no doubt much younger specimens were designated as paratypes. These specimens were previously considered by Dunn (1942) and Parker \& Dunn (1964) to be specimens of the type species of its genus, Caecilia tentaculata Linnaeus, 1758, which has a broad distribution in the Guianas and Amazon basin. Coloma et al. (2004) listed Venezuela, Surinam, French Guiana, Brazil, Peru, Ecuador and Colombia as countries of occurrence noting that, despite an absence of records, it presumably also occurs in Guyana. Cole et al. (2013) confirmed this presumption.

Taylor (1968:431) commenced his diagnosis of Caecilia pressula thus: "A species somewhat resembling Caecilia tentaculata, but with the body strongly compressed for most of its length (width 12.5, height 17.2, reaching a known length of $437 \mathrm{~mm}$ )." Although several other features are also mentioned in Taylor's diagnosis, including eye visibility, tentacle position, annulation pattern and squamation, none of these serve to further distinguish $C$. pressula from Linnaeus's long-standing species $C$. tentaculata, and I had long held doubts about the separation of these two species and hence the reality and taxonomic status of the former. Other than the description of its scales (Taylor, 1972), and its inclusion in faunal lists (as a Guyanese endemic, Cole et al., 2013), taxonomic summaries (e.g. Wilkinson \& Nussbaum, 2006; Wilkinson et al., 2011), and conservation assessments (as data deficient, Reynolds et al., 2004) there have been no additional reports of $C$. pressula in the literature and no additional specimens have been newly collected or identified in historical collections.

I recently examined the type series of Caecilia pressula at the AMNH (Fig. 1). The holotype, in my considered opinion, is a specimen of $C$. tentaculata. In terms of features that are most often relied upon for caecilian taxonomy (including colour, shape, size, positions of sensory organs, annulation, dentition, squamation) I find no compelling evidence to support the suggestion that AMNH 49475 is a member of a taxon that is distinct from C. tentaculata. Counts of meristic features (annulation, teeth) all fall within the known ranges for $C$. tentaculata (e.g. Taylor, 1968; Maciel \& Hoogmoed, 2011). While it is true that the type specimen of $C$. pressula is somewhat laterally compressed, the extent of this varies along the body and depends on how the specimen is held. Taylor (1968) reports midbody widths of 12.5 or $13 \mathrm{~mm}$ and a depth of $17.2 \mathrm{~mm}$. My measures are similar (width 12.9, depth $17 \mathrm{~mm}$ ) or not (width 16, depth 13) depending on how the specimen is held. In regions where the lateral 


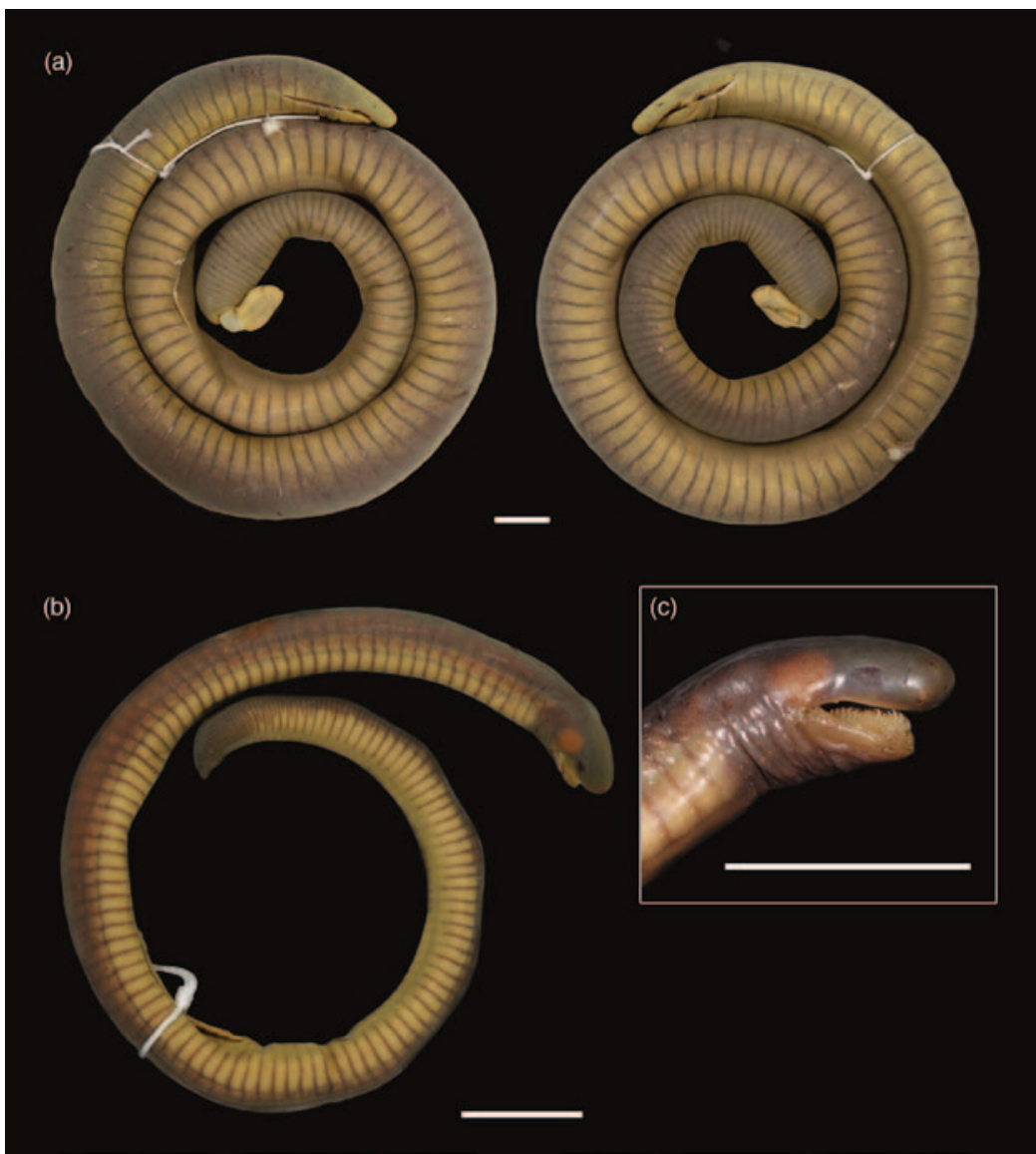

Figure 1. Caecilia pressula Taylor, 1968. (a) Holotype (AMNH A-19475), whole body. (b) 146 mm paratype (AMNH A-49471), whole body. (c) Close up of AMNH A-49471 showing vernal dentition. Scale bars are $10 \mathrm{~mm}$.

body wall is less flaccid, anteriorly (width 11, depth $10 \mathrm{~mm}$ ), at the level of the heart (width 14, depth 11 $\mathrm{mm}$ ) and a little anterior to the vent (width 13.5, depth $9.8 \mathrm{~mm}$ ), any compression is slight and dorsoventral rather than lateral. The midbody region of most specimens of Caecilia is slightly dorsoventrally compressed but lateral compression contingent upon how a specimen is held is not rare. The slightly flaccid body of the type specimen of $C$. pressula may result from inadequate filling of the coelom during initial fixation and it is certainly, in my opinion, no basis for inferring a different species. Lateral compression is not apparent in any of the paratype specimens of $C$. pressula which are all subcircular or slightly dorsoventrally compressed at midbody. In view of these observations and considerations, I place Caecilia pressula Taylor 1968 in the synonymy of Caecilia tentaculata Linnaeus, 1758.

The smallest specimens of the type series of Caecilia pressula (130 to $146 \mathrm{~mm}$, total length) were of interest to Parker \& Dunn (1964) because they have a non-adult dentition on their lower jaws (Fig. 1c). Their multiple rows of small spatulate teeth with tiny distal spicules are similar in crown form and arrangement to the teeth that had been reported in viviparous typhlonectid caecilian foetuses. Presumably based on Parker \& Dunn's (1964) description, Wake (1977) listed "foetal" teeth as evidence of viviparity in C. tentaculata. Current understanding is that similar teeth can be found in the hatchlings of some maternal dermatophagous (skin feeding) oviparous caecilian species (e.g. Kupfer et al., 2006; Wilkinson et al., 2008). Thus such teeth, renamed "vernal" by San Mauro et al. (2014); provide no compelling evidence of viviparity but do provide evidence of the nutrition of young (hatchlings or foetuses) through hypertrophied and lipidified skin or oviduct epithelia. Thus, in contrast to Wake (1977), San Mauro et al. (2014) interpreted Parker \& Dunn (1964) as providing evidence of maternal dermatophagy in Caecilia tentaculata, but both interpretations overlooked that the relevant specimens had been transferred to a different species. Caecilia tentaculata is a well-known species in the sense that there are many specimens in collections but despite the abundance of specimens, foetuses have never been found. Combined with this absence, the smallest specimens in the type series of $C$. pressula provide strong evidence that $C$. tentaculata is oviparous and practices maternal dermatophagy.

\section{ACKNOWLEDGEMENTS}

I am grateful to Chris Raxworthy and Lauren Vonnahme for facilitating my visits to the AMNH in September 2019 and February 2020, to The Natural History Museum, London for funding, to Gabriela B. Bittencourt-Silva for comments on the manuscript and help in preparing the figure, and to David Gower and Ramachandran Kotharambath for helpful reviews. 


\section{REFERENCES}

Cole, C.J., Townsend, C.R., Reynolds, R.P., MacCulloch, R.D. \& Lathrop, A. (2013). Amphibians and reptiles of Guyana, South America: illustrated keys, annotated species accounts, and a biogeographic synopsis. Proceedings of the Biological Society of Washington 125, 317-578.

Coloma, L.A., Ron, S., La Marca, E., Hoogmoed, M., Castro, F., Lynch, J. \& Wilkinson, M. (2004). Caecilia tentaculata. The IUCN Red List of Threatened Species 2004: e.T59530A11958955. Downloaded of 24 June 2020. https://dx.doi.org/10.2305/IUCN.UK.2004.RLTS. T59530A11958955.en.

Dunn, E.R. (1942). The American caecilians. Bulletin of The Museum of Comparative Zoology, Harvard 91, 339-540.

Kupfer, A., Müller, H., Antoniazzi, M.M., Jared, C., Greven, H., Nussbaum, R.A. \& Wilkinson, M. (2006). Parental investment by skin feeding in a caecilian amphibian. Nature 440, 926-929.

Maciel, A.O. \& Hoogmoed, M.S. (2011). Taxonomy and distribution of caecilian amphibians (Gymnophiona) of Brazilian Amazonia, with a key to their identification. Zootaxa 2984, 1-53.

Parker, H.W. \& Dunn, E.R. (1964). Dentitional metamorphosis in the Amphibia. Copeia 1964, 75-86.

Reynolds, R., Hoogmoed, M., MacCulloch, R., Gaucher, P. \& Wilkinson, M. (2004). Caecilia pressula. The IUCN Red List of Threatened Species 2004: e.T59526A11957102. Downloaded on 24 Jun 2020. https://dx.doi.org/10.2305/ IUCN.UK.2004.RLTS.T59526A11957102.en.
San Mauro, D., Gower, D.J., Müller, H., Loader, S.P., Zardoya, R., Nussbaum, R.A. \& Wilkinson, M. (2014). Life-history evolution and mitogenomic phylogeny of caecilian amphibians. Molecular Phylogenetics and Evolution 73, 177-189.

Taylor, E.H. (1968). Caecilians of the World. Lawrence: USA. 848 p. Taylor, E.H. (1972). Squamation in caecilians, with an atlas of scales. University of Kansas Science Bulletin 49, 989-1164.

Wake, M.H. (1977). The reproductive biology of caecilians: an evolutionary perspective. In: The Reproductive Biology of Amphibians, 73-101. Taylor, D.H. \& Guttman, S.I. (Eds.).

Wilkinson, M., Kupfer, A., Marques-Porto, R., Jeffkins, H., Antoniazzi, M.M. \& Jared, C. (2008). One hundred million years of skin feeding? Extended parental care in a Neotropical caecilian (Amphibia: Gymnophiona). Biology Letters 4, 358-361.

Wilkinson, M. \& Nussbaum, R.A. (2006). Caecilian phylogeny and classification. In: Reproductive Biology and Phylogeny of Amphibia, Volume 3 Gymnophiona, 53-92. J.-M. Exbrayat (Ed.), Enfield, USA.

Wilkinson, M., San Mauro, D., Sherratt, E. \& Gower, D.J. (2011). A nine-family classification of caecilians (Amphibia: Gymnophiona). Zootaxa 2874, 41-64.

Accepted: 24 June 2020 